\section{Actividades Comité Investigación}

\section{Proyectos que tienen continuidad}

1. Orientación de la enseñanza de la Lengua Materna al desarrollo de la competencia comunicativa en Educación Básica primaria y secundaria. Investigadores; Justo Abel Morales- María Teresa Cortés.

2. Diseño de formación de planes de desarrollo educativo en municipios de la región surcolombiana. Investigadores Miguel A. Tovar, Jesús María Vidal, Lino Muñoz y William Guzmán

3. El saber pedagógico en los docentes de la Universidad Surcolombiana. Investigador Nelson E. López.

4. La educación en el estado soberano del Tolima. Investigador Jairo Ramírez Bahamón.

5. Estudio longitudinal de un programa de Educación Física para preescolar. Investigador Luis Armando Muñoz.

6. Experiencias significativas de Educación Popular de adultos en Colombia. Coordinador Luis Ignacio Murcia.Proyectos aprobados que inician en 1995

1. Generación de un modelo teórico para la elaboración de Proyectos Educativos Institucionales en la ciudad de Neiva. Investigador, Fabio Losada Pérez, Alvaro E. Avendaño.

2. El significado sociocultural del fútbol en el Huila. Investigadores, Carlos B. Bonilla,
Josué Manchola Bello, Fabio Barbosa Mahecha.

3. La enseñanza del idioma inglés en la Educación Básica Primaria en Neiva. Investigadores; Luis Evelio Vanegas, Lilian Cecillia Zambrano.

4. Diseño y aplicación de una nueva estrategia para las cuatro formas de CurrículodePreescolar.Investigadoras

María Ligia Lavao de Serrato, María Sucel Ardila, Blanca Mary de Rivera y Gilma Guayara.

5. Qué tipo de texto necesita un niño huilense en su proceso de aprendizaje en el idioma inglés. Investigadores: Luis Humberto Alvarado, Edgar Alirio Insuasty, Luis Guillermo Moreno.

6. Alternativa curricular creativa para niños con parálisis cerebrat. Investigadora: Disnarda Mora de Calderón.

7. Universos culturales de los niños de 6 a 12 años de los estratos sociales bajo, medio, alto de la ciudad de Neiva.

Investigadora: Beatríz Polanía.

8. Examen humanístico del poema Tierra de Promisión de José Eustasio Rivera. Investigador: Jorge Elías Guebelly.

9. El quehacer del ser humano al servicio de la Educación : Buscando y entendiendo vamos aprendiendo. Investigador, José Antonio Ardila.

10. Programas líderes. Estrategia para el desarrollo personal de jóvenes de la ciudad de Neiva. 